\title{
New View of Ideals on PU-Algebra
}

\author{
Alaa Eldin I. Elkabany \\ Dep. of Mathematics \\ Faculty of Education \\ Ain Shams University
}

\author{
Mokhtar A. Abdel Naby \\ Dep. of Mathematics \\ Faculty of Education \\ Ain Shams University
}

Samy M. Mostafa
Dep. of Mathematics
Faculty of Education
Ain Shams University

\begin{abstract}
In this manuscript, we introduce a new concept, which called PU-algebra $X$. We state and prove some theorems about fundamental properties of it. Moreover, we give the concepts of a weak right self-maps, weak left self-maps and investigated some its properties. Further, we have proved that every associative PU-algebra is a group and every psemisimple algebra is an abelian group. We define the centre of a PU-algebra $\mathrm{X}$ and show that it is a p-semisimple subalgebra of $\mathrm{X}$, which consequently implies that every PUalgebra contains a $\mathrm{p}$-semisimple PU-algebra .Furthermore, we give the concepts of ideals ( -ideals, $\mathrm{i}=1,2,3,4)$ in PU-algebra , classified they into classes correspond to various formula and we have proved that, they are coincide .

Mathematics Subject Classification: 06F35, 03G25, 08A30.
\end{abstract}

\section{Keywords}

PU-algebra, ideals of PU-algebra, G-part and P-radical of a PU-algebra, homomorphism of PU-algebra.

\section{INTRODUCTION}

In 1966, Imai and Iseki [2] introduced two classes of abstract algebras: BCK-algebras and BCI-algebras. It is known that the class of BCK-algebras is a proper subclass of the class of BCI-algebras. In [1], $\mathrm{Hu}$ and $\mathrm{Li}$ introduced a wide class of abstract algebras: $\mathrm{BCH}$-algebras. They are shown that the class of BCI-algebras is a proper subclass of the class of BCH-algebras. In [7], Neggers and Kim introduced the notion of d-algebras, which is a generalization of BCK-algebras and investigated a relation between d-algebras and BCK-algebras. Neggers et al. introduced the notion of Q-algebras [8], which is a generalization of $\mathrm{BCH} / \mathrm{BCI} / \mathrm{BCK}$-algebras. Recently, Kim [3] defined a BE-algebra.[5] Meng, defined the notion of CIalgebra as a generalization of a BE-algebra.[4] Megalai and Tamilarasi introduced the notion of a TM-algebra which is a generalization of $\mathrm{BCK} / \mathrm{BCI} / \mathrm{BCH}$-algebras and several results are presented. In 2009 , C. Prabpayak and U. Leerawat $[9,10]$ introduced algebraic structure which is called KU-algebras , and studied ideals and congruencies in KU-algebras .They gave the concept of homomorphisms of KU-algebras and investigated some related properties. Moreover they derived some straightforward consequences of the relations between quotient $\mathrm{KU}$-algebras and isomorphisms and also investigated some of its properties. In this paper we will introduce a new algebraic structure called PU-algebra, which is a dual for TMalgebra and investigated severed basic properties. Moreover we derived new view of several ideals on PU-algebra and studied some properties of them.

\section{PRELIMINARIES}

Now we will recall some known concepts related to PUalgebra from the literature which will be helpful in further study of this article.

Definition 2.1[9].By a KU-algebra we mean an algebra (X, *, $0)$ of type $(2,0)$ with a single binary operation $*$ that satisfies the following identities: for any $\mathrm{x}, \mathrm{y}, \mathrm{z} \in \mathrm{X}$,

(ku1): $(\mathrm{x} * \mathrm{y}) *[(\mathrm{y} * \mathrm{z}) *(\mathrm{x} * \mathrm{z})]=0$,

(ku2): $\quad \mathrm{x} * 0=0$,

(ku3): $\quad 0 * \mathrm{x}=\mathrm{x}$

(ku4): $\quad \mathrm{x} * \mathrm{y}=0=\mathrm{y} * \mathrm{x}$ implies $\mathrm{x}=\mathrm{y}$.

Example 2.2: Let $X=\{0,1,2,3,4\}$ in which $*$ is defined by the following table:

\begin{tabular}{|c|c|c|c|c|c|}
\hline$*$ & 0 & 1 & 2 & 3 & 4 \\
\hline 0 & 0 & 1 & 2 & 3 & 4 \\
\hline 1 & 0 & 0 & 2 & 3 & 4 \\
\hline 2 & 0 & 1 & 0 & 3 & 3 \\
\hline 3 & 0 & 0 & 2 & 0 & 2 \\
\hline 4 & 0 & 0 & 0 & 0 & 0 \\
\hline
\end{tabular}

It is easy to show that $\mathrm{X}$ is a $\mathrm{KU}$ - algebra.

Lemma 2.3 [6]. In a KU-algebra ( $X, *, 0$ ), the following hold :

(i) $\mathrm{x} \leq \mathrm{y}$ imply $\mathrm{y} * \mathrm{z} \leq \mathrm{x} * \mathrm{z}$.

(ii) $\mathrm{z} *(\mathrm{y} * \mathrm{x})=\mathrm{y} *(\mathrm{z} * \mathrm{x})$

Definition 2.4. A PU-algebra is a non-empty set $X$ with a constant $0 \in \mathrm{X}$ and a binary operation * satisfying the following conditions:

(I) $0 * \mathrm{x}=\mathrm{x}$,

(II) $(\mathrm{x} * \mathrm{z}) *(\mathrm{y} * \mathrm{z})=\mathrm{y} * \mathrm{x}$ for any $\mathrm{x}, \mathrm{y}, \mathrm{z} \in \mathrm{X}$.

On $\mathrm{X}$ we can define a binary relation $" \leq$ " by: $\mathrm{x} \leq \mathrm{y}$ if and only if $\mathrm{y} * \mathrm{x}=0$.

Example 2.5. Let $X=\{0,1,2,3,4\}$ in which $*$ is defined by

\begin{tabular}{|l|l|l|l|l|l|}
\hline$*$ & 0 & 1 & 2 & 3 & 4 \\
\hline 0 & 0 & 1 & 2 & 3 & 4 \\
\hline 1 & 4 & 0 & 1 & 2 & 3 \\
\hline 2 & 3 & 4 & 0 & 1 & 2 \\
\hline 3 & 2 & 3 & 4 & 0 & 1 \\
\hline 4 & 1 & 2 & 3 & 4 & 0 \\
\hline
\end{tabular}

Using the algorithms in Appendix, we can prove that $(\mathrm{X}, *, 0)$ is a PU-algebra, but not a $\mathrm{KU}$-algebra , since $1 * 0=4 \neq 0$ .On the other hand, in Example 2.2., $\mathrm{X}$ is a $\mathrm{KU}$-algebra, but is not a PU-algebra since $(2 * 1) *(3 * 1)=1 * 0 \neq 3 * 2=2$, which means that PU-algebra and $\mathrm{KU}$-algebra are deferent. 
Example 2.6. $(\mathbb{R}, *, 0)$ where $*$ is defined by $\mathrm{x} * \mathrm{y}=\mathrm{y}-\mathrm{x}$ for all $\mathrm{x}, \mathrm{y} \in \mathbb{R}$ is a PU-algebra.

Proposition 2.7. In PU-algebra $(\mathrm{X}, *, 0)$ the following hold for all $\mathrm{x}, \mathrm{y}, \mathrm{z} \in \mathrm{X}$ :
(a) $\mathrm{x} * \mathrm{x}=0$
(b) $(\mathrm{x} * \mathrm{z}) * \mathrm{z}=\mathrm{x}$
(d) $\mathrm{x} *(\mathrm{y} * \mathrm{x})=\mathrm{y} * 0$.
(e) $(\mathrm{x} * \mathrm{y}) * 0=\mathrm{y} * \mathrm{x}$
(1) $x=y$,
(2) $\mathrm{x} * \mathrm{z}=\mathrm{y} * \mathrm{z}$,
(3) $\mathrm{z} * \mathrm{x}=\mathrm{z} * \mathrm{y}$.

(c) $\mathrm{x} *(\mathrm{y} * \mathrm{z})=\mathrm{y} *(\mathrm{x} * \mathrm{z})$

(f) If $\mathrm{x} \leq \mathrm{y}$, then $\mathrm{x} * 0=\mathrm{y} * 0$.

$(\mathrm{g})(\mathrm{x} * \mathrm{y}) * 0=(\mathrm{x} * \mathrm{z}) *(\mathrm{y} * \mathrm{z})$

(h) $\mathrm{x} * \mathrm{y} \leq \mathrm{z}$ if and only if $\mathrm{z} * \mathrm{y} \leq \mathrm{x}$.

(i) $\mathrm{x} \leq \mathrm{y}$ if and only if $\mathrm{y} * \mathrm{z} \leq \mathrm{x} * \mathrm{z}$.

(j) In PU-algebra $(\mathrm{X}, *, 0)$, the following are equivalent:

(k) The right and the left cancellation laws hold in X.

\section{Proof:}

(a) Putting $\mathrm{x}=\mathrm{y}=0$ in Definition 2.4. (II), we get $(0 * \mathrm{z}) *(0$ $* \mathrm{z})=0 * 0$. Then

$$
\mathrm{z} * \mathrm{z}=0
$$

(by Definition 2.4. (I))

(b) $(\mathrm{x} * \mathrm{z}) * \mathrm{z}=(\mathrm{x} * \mathrm{z}) *(0 * \mathrm{z})$

(by Definition 2.4. (I))

$$
=0 * \mathrm{x}=\mathrm{x}
$$

(by Definition 2.4. (I), (II))

(c) $\mathrm{x} *(\mathrm{y} * \mathrm{z})=[(\mathrm{x} * \mathrm{z}) * \mathrm{z}] *(\mathrm{y} * \mathrm{z}) \quad($ from $(\mathrm{b}))$

$$
=\mathrm{y} *(\mathrm{x} * \mathrm{z}) \quad(\text { by Definition 2.4. (II)). }
$$

(d) $\mathrm{x} *(\mathrm{y} * \mathrm{x})=\mathrm{y} *(\mathrm{x} * \mathrm{x})$ (from Proposition 2.7 (c))

$$
=\mathrm{y} * 0
$$

(e) $(\mathrm{x} * \mathrm{y}) * 0=(\mathrm{x} * \mathrm{y}) *(\mathrm{y} * \mathrm{y})$

(from Proposition 2.7 (a))

$$
=\mathrm{y} * \mathrm{x}
$$

(by Definition 2.4. (II)).

(f) $\mathrm{x} \leq \mathrm{y} \Rightarrow \mathrm{y} * \mathrm{x}=0$ (by the definition of PU-algebra) (d)).

$$
\Rightarrow \mathrm{x} * 0=\mathrm{x} *(\mathrm{y} * \mathrm{x})=\mathrm{y} * 0 \text { (from Proposition } 2.7
$$

$(\mathrm{g})(\mathrm{x} * \mathrm{y}) * 0=\mathrm{y} * \mathrm{x}$

(from Proposition 2.7 (e))

$$
=(\mathrm{x} * \mathrm{z}) *(\mathrm{y} * \mathrm{z}) \quad \text { (by Definition 2.4. (II)). }
$$

(h) $\mathrm{x} * \mathrm{y} \leq \mathrm{z} \Leftrightarrow \mathrm{z} *(\mathrm{x} * \mathrm{y})=0 \Leftrightarrow \mathrm{x} *(\mathrm{z} * \mathrm{y})=0$ (from Proposition 2.7 (c))

$$
\Leftrightarrow \mathrm{z} * \mathrm{y} \leq \mathrm{x} .
$$

(i) $\mathrm{x} \leq \mathrm{y} \Leftrightarrow \mathrm{y} * \mathrm{x}=0 \quad$ (by the definition of PU-algebra)

$$
\begin{aligned}
& \Leftrightarrow(\mathrm{x} * \mathrm{z}) *(\mathrm{y} * \mathrm{z})=0 \quad \text { (by Definition 2.4. (II)) } \\
& \Leftrightarrow \mathrm{y} * \mathrm{z} \leq \mathrm{x} * \mathrm{z} .
\end{aligned}
$$

(j) $((1) \Rightarrow(3))$ : Clear.
$((3) \Rightarrow(2)): \mathrm{z} * \mathrm{x}=\mathrm{z} * \mathrm{y} \Rightarrow(\mathrm{x} * \mathrm{z}) * 0=(\mathrm{y} * \mathrm{z}) * 0 \quad$ (from Proposition 2.7 (e))

$* 0$

Proposition 2.7 (b)).

$$
\Rightarrow((\mathrm{x} * \mathrm{z}) * 0) * 0=((\mathrm{y} * \mathrm{z}) * 0)
$$

$((2) \Rightarrow(1)): \mathrm{x} * \mathrm{z}=\mathrm{y} * \mathrm{z} \Rightarrow(\mathrm{x} * \mathrm{z}) * \mathrm{z}=(\mathrm{y} * \mathrm{z}) * \mathrm{z}$

(b)).

$\Rightarrow \mathrm{x}=\mathrm{y}($ from Proposition 2.7

(k) Follows directly from (j).

Proposition 2.8. If $(\mathrm{X}, *, 0)$ is a PU-algebra, then for any $\mathrm{x}, \mathrm{y}$, $\mathrm{z} \in \mathrm{X}$,

(1) $(\mathrm{z} * \mathrm{x}) *(\mathrm{z} * \mathrm{y})=\mathrm{x} * \mathrm{y}$,

(2) $(\mathrm{x} * \mathrm{y}) * \mathrm{z}=(\mathrm{z} * \mathrm{y}) * \mathrm{x}$.

\section{Proof:}

(1) By the definition of PU-algebra, we have that

$(\mathrm{z} * \mathrm{x}) *(\mathrm{z} * \mathrm{y})=[(\mathrm{x} * \mathrm{y}) *(\mathrm{z} * \mathrm{y})] *[0 *(\mathrm{z} * \mathrm{y})]=0 *(\mathrm{x}$

$* \mathrm{y})=\mathrm{x} * \mathrm{y}$.

(2) $(\mathrm{x} * \mathrm{y}) * \mathrm{z}=[\mathrm{z} *(\mathrm{x} * \mathrm{y})] * 0 \quad$ (from Proposition $2.7(\mathrm{e}))$

$$
\begin{array}{ll}
=[\mathrm{x} *(\mathrm{z} * \mathrm{y})] * 0 & \text { (from Proposition } 2.7(\mathrm{c})) \\
=(\mathrm{z} * \mathrm{y}) * \mathrm{x} & \text { (from Proposition } 2.7(\mathrm{e})) .
\end{array}
$$

Lemma 2.9. If $(\mathrm{X}, *, 0)$ is a PU-algebra, then $(\mathrm{X}, \leq)$ is a partially ordered set.

Proof: By Proposition 2.7. (a), we have that $\mathrm{x} * \mathrm{x}=0$ i.e. $\mathrm{x} \leq$ $\mathrm{x}$

Let $\mathrm{x} \leq \mathrm{y}, \mathrm{y} \leq \mathrm{x}$, then $\mathrm{x} * \mathrm{y}=0=\mathrm{y} * \mathrm{x}$. It follows that

$$
\mathrm{x}=0 * \mathrm{x} \quad \text { (by Definition 2.4. (I)) }
$$

,(I))

$=(\mathrm{y} * \mathrm{x}) *(0 * \mathrm{x})=0 * \mathrm{y}=\mathrm{y} \quad$ (by Definition 2.4. (II)

Let $\mathrm{x} \leq \mathrm{y}, \mathrm{y} \leq \mathrm{z}$ i.e. $\mathrm{y} * \mathrm{x}=0=\mathrm{z} * \mathrm{y}$. It follows that

$$
\begin{aligned}
\mathrm{z} * \mathrm{x} & =0 *(\mathrm{z} * \mathrm{x}) \quad \text { (by Definition 2.4. (I)) } \\
& =(\mathrm{y} * \mathrm{x}) *(\mathrm{z} * \mathrm{x})=\mathrm{z} * \mathrm{y}=0 \quad \text { (by Definition 2.4. (II)) }
\end{aligned}
$$

i.e. $\mathrm{x} \leq \mathrm{z}$. Therefore $(\mathrm{X}, \leq)$ is a partially ordered set.

Remark 2.10. Every PU-algebra $(\mathrm{X}, *, 0)$ satisfying $(\mathrm{y} * \mathrm{x}) * \mathrm{x}$ $=\mathrm{y} * \mathrm{x}$ for all

$\mathrm{x}, \mathrm{y} \in \mathrm{X}$ is a trivial algebra.

Proof: Putting $\mathrm{x}=\mathrm{y}$ in the equation $(\mathrm{y} * \mathrm{x}) * \mathrm{x}=\mathrm{y} * \mathrm{x}$, we have $0 * \mathrm{x}=0$. By Definition 2.4. (I), $\mathrm{x}=0$. Hence $\mathrm{X}$ is a trivial algebra.

Proposition 2.11. If $(\mathrm{X}, *, 0)$ is a PU-algebra, then $(\mathrm{x} * \mathrm{y}) *$ $(\mathrm{z} * \mathrm{u})=(\mathrm{x} * \mathrm{z}) *(\mathrm{y} * \mathrm{u})$ for all $\mathrm{x}, \mathrm{y}, \mathrm{z}$ and $\mathrm{u} \in \mathrm{X}$.

Proof: Let $(\mathrm{X}, *, 0)$ be a PU-algebra, then for all $\mathrm{x}, \mathrm{y}, \mathrm{z}$ and $\mathrm{u}$ $\in \mathrm{X}$ we have that

$(\mathrm{x} * \mathrm{y}) *(\mathrm{z} * \mathrm{u})=0 *[(\mathrm{x} * \mathrm{y}) *(\mathrm{z} * \mathrm{u})]$ (by Definition 2.4. (I))

$$
=[(\mathrm{y} * \mathrm{u}) *(\mathrm{y} * \mathrm{u})] *[(\mathrm{x} * \mathrm{y}) *(\mathrm{z} * \mathrm{u})]
$$

(from Proposition 2.7 (a)) 
(from Proposition 2.8 (2))

$$
=[[(\mathrm{x} * \mathrm{y}) *(\mathrm{z} * \mathrm{u})] *(\mathrm{y} * \mathrm{u})] *(\mathrm{y} * \mathrm{u})
$$

(from Proposition 2.8 (2))

$$
=[[(\mathrm{y} * \mathrm{u}) *(\mathrm{z} * \mathrm{u})] *(\mathrm{x} * \mathrm{y})] *(\mathrm{y} * \mathrm{u})
$$

(by Definition 2.4. (II))

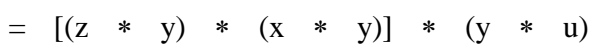

$$
=\quad(\mathrm{x}
$$

(by Definition 2.4. (II)).

Corollary 2.12. If $(\mathrm{X}, *, 0)$ is a PU-algebra, then $(\mathrm{x} * \mathrm{y}) * \mathrm{z}=$ $(\mathrm{x} * 0) *(\mathrm{y} * \mathrm{z})$ for all $\mathrm{x}, \mathrm{y}$ and $\mathrm{z} \in \mathrm{X}$.

Proof: Let $(\mathrm{X}, *, 0)$ be a PU-algebra, then for all $\mathrm{x}, \mathrm{y}, \mathrm{z} \in \mathrm{X}$ we have that $(\mathrm{x} * \mathrm{y}) * \mathrm{z}=(\mathrm{x} * \mathrm{y}) *(0 * \mathrm{z})$ (by Definition 2.4. (I))

\section{(from Proposition 2.11).}

$$
0) \quad * \quad(\mathrm{y} \quad * \quad \mathrm{z})
$$

All material on each page should fit within a rectangle of $18 \mathrm{x}$ $23.5 \mathrm{~cm}(7 " \mathrm{x} 9.25 ")$, centered on the page, beginning $2.54 \mathrm{~cm}$ (1") from the top of the page and ending with $2.54 \mathrm{~cm}(1 ")$ from the bottom. The right and left margins should be $1.9 \mathrm{~cm}$ (.75"). The text should be in two $8.45 \mathrm{~cm}\left(3.33^{\prime \prime}\right)$ columns with a $.83 \mathrm{~cm}(.33 ")$ gutter.

\section{G-PART AND P-RADICAL OF A PU - ALGEBRA}

Definition 3.1. Let $X$ be a PU-algebra. For any subset $S$ of $X$, we define $\mathrm{G}(\mathrm{S})=\{\mathrm{x} \in \mathrm{S}: \mathrm{x} * 0=\mathrm{x}\}$, in particular if $\mathrm{S}=\mathrm{X}$, then we say that $G(X)$ is the G-part of $X$. It is clear that if $(X$, $*, 0)$ is a PU-algebra and if $\mathrm{x} \in \mathrm{G}(\mathrm{X})$, then $\mathrm{x}=0 * \mathrm{x}=\mathrm{x} * 0$. For any PU-algebra $X$, the set $B(X)=\{x \in X: x * 0=0\}$ is called a P-radical of $\mathrm{X}$. A PU-algebra $\mathrm{X}$ is said to be $\mathrm{P}$ semisimple, if every element of $\mathrm{X}$ is minimal, i.e

$B(X)=\{0\}$. The following property is obvious: $G(X) \cap B(X)=$ $\{0\}$.we define
$A(a, b)=\left\{x \in X, b \leq a^{*} x\right\}$ and the set $\left\{x \in X,\left(x^{*}\right.\right.$ is called the center of $X$.

Proposition 3.2. Let $(\mathrm{X}, *, 0)$ be a PU-algebra and $\mathrm{x}, \mathrm{y}, \mathrm{z} \in$ $\mathrm{X}$, then

$$
\begin{aligned}
& \text { (a) } y \in G(X) \Leftrightarrow x *(y * x)=y . \\
& \text { (b) } y \in B(X) \Leftrightarrow x *(y * x)=0 . \\
& \text { (C) } x \in G(X) \Leftrightarrow x * 0 \in G(X) .
\end{aligned}
$$

Proof: (a) By Proposition 2.7. (d), $x *(y * x)=y * 0=y \Leftrightarrow y$ $\in \mathrm{G}(\mathrm{X})$.

(b) By Proposition 2.7. (d), $\mathrm{x} *(\mathrm{y} * \mathrm{x})=\mathrm{y} * 0=0 \Leftrightarrow \mathrm{y} \in$ $\mathrm{B}(\mathrm{X})$.

$$
\begin{aligned}
& \text { (c) } \mathrm{x} \in \mathrm{G}(\mathrm{X}) \Leftrightarrow \mathrm{x} * 0=\mathrm{x} \\
& \mathrm{G}(\mathrm{X})) \\
& \text { (by the definition of } \\
& \Leftrightarrow \mathrm{x} * 0=(\mathrm{x} * 0) * 0 \quad \text { (by Proposition } 2.7(\mathrm{~b})) \\
& \Leftrightarrow \mathrm{X} * 0 \in \mathrm{G}(\mathrm{X}) \text {. }
\end{aligned}
$$

Proposition 3.3. The following are equivalent in PU-algebra $(\mathrm{X}, *, 0)$ :
(1) $x=y * z$,
(2) $y=z * x$

(3) $z=x * y$ for all $x, y, z \in G(X)$.

Proof: $(1) \Rightarrow(2): x=y * z \Rightarrow z * x=z *(y * z)=y * 0=y$ (by Proposition 2.7 (d) and the definition of $\mathrm{G}(\mathrm{X})$ ).

(2) $\Rightarrow(3): y=z * x \Rightarrow x * y=x *(z * x)=z * 0=z$.

(3) $\Rightarrow(1): z=x * y \Rightarrow y * z=y *(x * y)=x * 0=x$.

Lemma 3.4. If $G(X)=X$, then $X$ is $P$-semisimple.

Proof: Assume that $\mathrm{G}(\mathrm{X})=\mathrm{X}$. Then $\{0\}=\mathrm{G}(\mathrm{X}) \cap \mathrm{B}(\mathrm{X})=\mathrm{X}$ $\cap \mathrm{B}(\mathrm{X})=\mathrm{B}(\mathrm{X})$, and hence $\mathrm{X}$ is $\mathrm{P}$-semisimple.

Definition 3.5. Let $(\mathrm{X}, *, 0)$ be a PU-algebra. For a fixed a $\in$ $\mathrm{X}$.

The map Ra: $\mathrm{X} \rightarrow \mathrm{X}$ given by $\operatorname{Ra}(\mathrm{y})=\mathrm{y} *$ a for all $\mathrm{y} \in \mathrm{X}$ is called a right self-maps of $X$. Similarly the map La: $X \rightarrow X$ given by $\operatorname{La}(y)=a * y$ for all $y \in X$ is called a left self-maps of $X$.

Definition 3.6. Let $(X, *, 0)$ be a PU-algebra. For a fixed a $\in$ X.

The map Ta: $\mathrm{X} \rightarrow \mathrm{X}$ given by $\mathrm{Ta}(\mathrm{y})=(\mathrm{y} * \mathrm{a}) *(\mathrm{a} * 0)$ for all $y \in X$ is called a weak right self-maps of $X$.

Similarly the map Ma: X $\rightarrow X$ given by $\mathrm{Ma}(\mathrm{y})=(\mathrm{a} * 0) *(\mathrm{a}$ $* \mathrm{y})$ for all $\mathrm{y} \in \mathrm{X}$ is called a weak left self-maps of $\mathrm{X}$.

Theorem 3.7. Let $(\mathrm{X}, *, 0)$ be a PU-algebra, then $\mathrm{Lx}=\mathrm{Mx}$ o Lx if and only if $\quad(\mathrm{x} * 0) *(\mathrm{x} *(\mathrm{x} * \mathrm{y}))=\mathrm{x} * \mathrm{y}$ for all $\mathrm{x}, \mathrm{y} \in \mathrm{X}$.

Proof: $(\Rightarrow)$ : Let $(\mathrm{X}, *, 0)$ be a PU-algebra and $\mathrm{Lx}=\mathrm{Mx}$ o $\mathrm{Lx}$ for all $\mathrm{x} \in \mathrm{X}$. Then $\quad \mathrm{x} * \mathrm{y}=\mathrm{Lx}(\mathrm{y})=(\mathrm{Mx} O \mathrm{Lx})(\mathrm{y})=$ $\operatorname{Mx}(\operatorname{Lx}(\mathrm{y}))=\operatorname{Mx}(x * y)=(x * 0) *(x *(x * y))$ for all $\mathrm{x}, \mathrm{y} \in$ $\mathrm{X}$.

$(\Leftarrow)$ : Let $(\mathrm{X}, *, 0)$ be a PU-algebra and $(\mathrm{x} * 0) *(\mathrm{x} *(\mathrm{x} * \mathrm{y}))$ $=\mathrm{x} * \mathrm{y}$ for all $\mathrm{x}, \mathrm{y} \in \mathrm{X}$, then $\operatorname{Lx}(\mathrm{y})=\mathrm{x} * \mathrm{y}=(\mathrm{x} * 0) *(\mathrm{x} *$ $\operatorname{Lx}(\mathrm{y}))=\operatorname{Mx}(\operatorname{Lx}(\mathrm{y}))=(\operatorname{Mx}$ o Lx $)(\mathrm{y})$. Hence $\quad \mathrm{Lx}=\mathrm{Mx}$ D) 2 x. $0=x\}$

Definition 3.8. A non-empty subset I of a PU-algebra (X, *, 0 ) is called a PU-sub algebra of $\mathrm{X}$ if $\mathrm{x} * \mathrm{y} \in \mathrm{I}$ whenever $\mathrm{x}, \mathrm{y}$ $\in \mathrm{I}$.

Lemma 3.9. If $(\mathrm{X}, *, 0)$ is a $\mathrm{PU}$-algebra, then:

(a) $G(X)$ is a PU-sub algebra of $X$.

(b) $\mathrm{B}(\mathrm{X})$ is a PU-sub algebra of $\mathrm{X}$.

Proof: (a) Assume that $(\mathrm{X}, *, 0)$ is a PU-algebra and $\mathrm{x}, \mathrm{y} \in$ $\mathrm{G}(\mathrm{X})$, i.e. $\mathrm{x} * 0=\mathrm{x}, \quad \mathrm{y} * 0=\mathrm{y}$. Then by Proposition 2.7 . $(\mathrm{g}),(\mathrm{x} * \mathrm{y}) * 0=(\mathrm{x} * 0) *(\mathrm{y} * 0)=\mathrm{x} * \mathrm{y}$. Hence $\mathrm{x} * \mathrm{y} \in$ $\mathrm{G}(\mathrm{X})$. Therefore $\mathrm{G}(\mathrm{X})$ is a PU-sub algebra of $\mathrm{X}$.

(b) Assume that $(\mathrm{X}, *, 0)$ is a PU-algebra and $\mathrm{x}, \mathrm{y} \in \mathrm{B}(\mathrm{X})$, i.e. $\mathrm{x} * 0=0=\mathrm{y} * 0$. Then by Proposition 2.7. $(\mathrm{g}),(\mathrm{x} * \mathrm{y}) * 0=$ $(\mathrm{x} * 0) *(\mathrm{y} * 0)=0 * 0=0$. Hence Therefore $\mathrm{B}(\mathrm{X})$ is a PU-sub algebra of $\mathrm{X}$. $\mathrm{x} * \mathrm{y} \in \mathrm{B}(\mathrm{X})$

Lemma 3.10. If $(X, *, 0)$ is a PU-algebra, then

(a) $\mathrm{x} *(\mathrm{y} * \mathrm{z})=(\mathrm{x} * \mathrm{y}) * \mathrm{z}$ for all $\mathrm{x} \in \mathrm{G}(\mathrm{X})$ and $\mathrm{y}, \mathrm{z} \in \mathrm{X}$

(b) $x * y=y * x$ for all $x, y \in G(X)$.

Proof:

(a) By the definition of $G(X)$ and Proposition 2.11, we have 
$\mathrm{x} *(\mathrm{y} * \mathrm{z})=(\mathrm{x} * 0) *(\mathrm{y} * \mathrm{z})=(\mathrm{x} * \mathrm{y}) *(0 * \mathrm{z})=(\mathrm{x} * \mathrm{y}) * \mathrm{z}$ (by Definition 2.4.(I)).

(b) By Definition 2.4. (I) and the definition of $\mathrm{G}(\mathrm{X})$, we have

$$
\begin{aligned}
\mathrm{x} * \mathrm{y} & =(0 * \mathrm{x}) *(\mathrm{y} * 0) \\
& =(0 * \mathrm{y}) *(\mathrm{x} * 0)
\end{aligned}
$$

(by Proposition

$$
=\mathrm{y} * \mathrm{x}
$$

(by Definition 2.4. (I) and the definition of $\mathrm{G}(\mathrm{X})$ )

Theorem 3.11. If $(X, *, 0)$ is PU-algebra, then $G(X)$ is an abelian group.

Proof: Let $(\mathrm{X}, *, 0)$ be a PU-algebra. Then for all $\mathrm{x} \in \mathrm{G}(\mathrm{X})$ we have

$\mathrm{x}=0 * \mathrm{x}=\mathrm{x} * 0$. By Proposition 2.7. (a), we have $\mathrm{x} * \mathrm{x}=0$ for all $\mathrm{x} \in \mathrm{G}(\mathrm{X})$. By Lemma 3.10. (b), we have $\mathrm{x} * \mathrm{y}=\mathrm{y} * \mathrm{x}$ for all $x, y \in G(X)$. Finally by Lemma 3.10. (a), we have $x *$ $(\mathrm{y} * \mathrm{z})=(\mathrm{x} * \mathrm{y}) * \mathrm{z}$ for all $\mathrm{x}, \mathrm{y}$ and $\mathrm{z} \in \mathrm{G}(\mathrm{X})$. Therefore $\mathrm{G}(\mathrm{X})$ is an abelian group.

In Example 2.5., (X, *, 0) is a PU-algebra, but associatively does not hold, since $\quad 1 *(2 * 1)=2 * 0=3 \neq 0=1 * 1$ $=(1 * 2) * 1$

Theorem 3.12. If $(X, *, 0)$ is associative PU-algebra, then $\mathrm{G}(\mathrm{X})=\mathrm{X}$ and $\mathrm{B}(\mathrm{X})=\{0\}$.

Proof: If $(X, *, 0)$ is associative PU-algebra, then clearly $\mathrm{G}(\mathrm{X})$ $\subseteq \mathrm{X}$. If $\mathrm{x} \in \mathrm{X}$, then $\mathrm{x} * 0=\mathrm{x} *(\mathrm{x} * \mathrm{x})=(\mathrm{x} * \mathrm{x}) * \mathrm{x}=0 * \mathrm{x}$ $=x$, and it follows that $x \in G(X)$. Hence $\quad X \subseteq G(X)$. Thus $\mathrm{G}(\mathrm{X})=\mathrm{X}$. For the second part, clearly $\{0\} \subseteq \mathrm{B}(\mathrm{X})$. If $\mathrm{X}$ $\in \mathrm{B}(\mathrm{X})$, then $\mathrm{x}=0 * \mathrm{x}=(\mathrm{x} * \mathrm{x}) * \mathrm{x}=\mathrm{x} *(\mathrm{x} * \mathrm{x})=\mathrm{x} * 0=0$ and $\mathrm{B}(\mathrm{X}) \subseteq\{0\}$. Thus $\mathrm{B}(\mathrm{X})=\{0\}$.

Theorem 3.13. Every associative PU-algebra $(X, *, 0)$ is a group.

Proof: Putting $\mathrm{x}=\mathrm{y}=\mathrm{z}$ in the associative law $(\mathrm{x} * \mathrm{y}) * \mathrm{z}=\mathrm{x}$ $*(\mathrm{y} * \mathrm{z})$ and using Definition 2.4. (I) and Proposition 2.7 (a), we obtain $0 * \mathrm{x}=\mathrm{x} * 0=\mathrm{x}$. This means that 0 is the identity of X. Also by Proposition 2.7 (a), every element $\mathrm{x}$ of $\mathrm{X}$ has an inverse. Therefore $(\mathrm{X}, *)$ is a group.

\section{NEW VIEW OF IDEALS ON PU- ALGEBRA}

Definition 4.1[9]. A non-empty subset I of a PU-algebra (X, $*, 0)$ is called an ideal of $\mathrm{X}$ if for any $\mathrm{x}, \mathrm{y} \in \mathrm{X}$,

(i) $0 \in I$,

(ii) $\mathrm{x} * \mathrm{y}, \mathrm{x} \in \mathrm{I}$ imply $\mathrm{y} \in \mathrm{I}$

Definition 4.2[9]. A non empty subset I of a PU-algebra $\mathrm{X}$ is called a KU-ideal of $\mathrm{X}$ if it satisfies the following conditions:

(1) $0 \in I$,

(2) $\mathrm{x} *(\mathrm{y} * \mathrm{z}) \in \mathrm{I}, \mathrm{y} \in \mathrm{I}$ imply $\mathrm{x} * \mathrm{z} \in \mathrm{I}$, for all $\mathrm{x}, \mathrm{y}, \mathrm{z} \in$ $\mathrm{X}$

Theorem 4.3. Let $(\mathrm{X}, *, 0)$ be a PU-algebra and let I be a nonempty subset of $X$. Then $I$ is an ideal of $X$ if and only if $I$ is a KU-ideal of $\mathrm{X}$

Proof: $(\Rightarrow)$ : Suppose that I is an ideal of X. It is clear that $0 \in$ I. Let $\mathrm{x} *(\mathrm{y} * \mathrm{z}) \in \mathrm{I}$ and $\mathrm{y} \in \mathrm{I}$, it follows by Proposition 2.7.(c) that $y *(x * z) \in I$. Since I is an ideal of $X$, then $x * z$ $\in \mathrm{I}$. Hence $\mathrm{I}$ is a KU-ideal of $\mathrm{X}$.

$(\Leftarrow)$ : Suppose that $\mathrm{I}$ is a KU-ideal of $\mathrm{X}$. It is clear that $0 \in \mathrm{I}$. Put $\mathrm{x}=0$ in the definition of KU-ideal we have that $0 *(\mathrm{y} * \mathrm{z})$ $\in \mathrm{I}, \mathrm{y} \in \mathrm{I}$ imply $0 * \mathrm{z} \in \mathrm{I}$. By using the definition of PUalgebra, we have $0 *(\mathrm{y} * \mathrm{z})=\mathrm{y} * \mathrm{z}$ and $0 * \mathrm{z}=\mathrm{z}$, i.e. $\mathrm{y} * \mathrm{z} \in$ $\mathrm{I}, \mathrm{y} \in \mathrm{I}$ imply $\mathrm{z} \in \mathrm{I}$. Therefore $\mathrm{I}$ is an ideal of $\mathrm{X}$.

Example 4.4. Let $X=\{0, a, b, c\}$ in which $*$ is defined by the following table:

\begin{tabular}{|l|l|l|l|l|}
\hline$*$ & 0 & a & b & c \\
\hline 0 & 0 & a & b & c \\
\hline a & a & 0 & c & b \\
\hline b & b & c & 0 & a \\
\hline c & c & b & a & 0 \\
\hline
\end{tabular}

Using the algorithms in Appendix , we can prove that $(\mathrm{X}, *$, 0 ) is a PU-algebra. It is easy to show that $\mathrm{I} 1=\{0, \mathrm{a}\}, \mathrm{I} 2=\{0$, b $\}, \quad I 3=\{0, c\}$ are KU-ideals of $X$.

Definition 4.5. A non-empty subset I of a PU-algebra (X,*, 0 ) is called a PU1-ideal of $X$ if it satisfies the following conditions:

(i) $0 \in \mathrm{I}$

(ii) $\mathrm{y} * \mathrm{x}, \mathrm{x} * \mathrm{z} \in \mathrm{I}$ imply $\mathrm{y} * \mathrm{z} \in \mathrm{I}$, for all $\mathrm{x}, \mathrm{y}, \mathrm{z} \in \mathrm{X}$

Theorem 4.6. Let $(\mathrm{X}, *, 0)$ be a PU-algebra and let I be a nonempty subset of $\mathrm{X}$. Then $\mathrm{I}$ is an ideal of $\mathrm{X}$ if and only if $\mathrm{I}$ is a PU1-ideal of $\mathrm{X}$.

Proof: $(\Rightarrow)$ : Suppose that I is an ideal of $X$. It is clear that $0 \in$ I. Let $\mathrm{y} * \mathrm{x}, \mathrm{x} * \mathrm{z} \in \mathrm{I}$. Since $\mathrm{y} * \mathrm{x}=(\mathrm{x} * \mathrm{z}) *(\mathrm{y} * \mathrm{z})$ (by Definition 2.4. (II)), then we have $(\mathrm{x} * \mathrm{z}) *(\mathrm{y} * \mathrm{z}) \in \mathrm{I}$ and $\mathrm{x} *$ $\mathrm{z} \in \mathrm{I}$. It follows by the definition of ideal that $\mathrm{y} * \mathrm{z} \in \mathrm{I}$. Therefore I is a PU1-ideal of X.

$(\Leftarrow)$ : Suppose that I is a PU1-ideal of X. It is clear that $0 \in \mathrm{I}$. Put $y=0 \quad$ in the definition of PU1-ideal and by using the definition of PU-algebra, we get $\quad \mathrm{x} \in \mathrm{I}, \mathrm{x} * \mathrm{z} \in$ I imply $z \in I$. Therefore $I$ is an ideal of $X$.

Definition 4.7. A non-empty subset I of a PU-algebra $(\mathrm{X}, *$, 0 ) is called a PU2-ideal of $X$ if for any $x, y, z \in X$,

(i) $0 \in I$,

(ii) $(\mathrm{x} * \mathrm{y}) * \mathrm{z} \in \mathrm{I}, \mathrm{z} * \mathrm{y} \in \mathrm{I}$ imply $\mathrm{x} \in \mathrm{I}$.

Theorem 4.8. Let $(\mathrm{X}, *, 0)$ be a PU-algebra and let I be a nonempty subset of $\mathrm{X}$. Then $\mathrm{I}$ is an ideal of $\mathrm{X}$ if and only if $\mathrm{I}$ is a PU2-ideal of $X$.

Proof: $(\Rightarrow)$ : It is clear that $0 \in \mathrm{I}$. Let $(\mathrm{x} * \mathrm{y}) * \mathrm{z} \in \mathrm{I}, \mathrm{z} * \mathrm{y} \in$ I. Since $(\mathrm{X}, *, 0)$ is $\mathrm{PU}$-algebra, then $(\mathrm{z} * \mathrm{y}) * \mathrm{x}=(\mathrm{x} * \mathrm{y}) *$ $\mathrm{Z} \in \mathrm{I}$, it follows by the definition of an ideal of PU-algebra that $\mathrm{x} \in \mathrm{I}$. Hence $\mathrm{I}$ is a PU2-ideal of $\mathrm{X}$.

$(\Leftarrow)$ :

It is clear that $0 \in \mathrm{I}$. Let $\mathrm{x} * \mathrm{y} \in \mathrm{I}, \mathrm{x} \in \mathrm{I}$. It follows by the definition of $\quad$ PU-algebra and its properties that $\mathrm{x} * \mathrm{y}$ $=(\mathrm{y} * \mathrm{x}) * 0 \in \mathrm{I}$ and $\mathrm{x}=0 * \mathrm{x} \in \mathrm{I}$. Since $\mathrm{I}$ is a PU2-ideal of a PU-algebra, then $\mathrm{y} \in \mathrm{I}$. Hence $\mathrm{I}$ is an ideal of $\mathrm{X}$. 
Definition 4.9. A non-empty subset I of a PU-algebra (X, *, 0 ) is called a PU3-ideal of $\mathrm{X}$ if,
(i) $0 \in \mathrm{I}$,
(ii) $(\mathrm{a} *(\mathrm{~b} * \mathrm{x})) * \mathrm{x} \in \mathrm{I}$, for all $\mathrm{a}, \mathrm{b} \in \mathrm{I}$ and $\mathrm{x} \in \mathrm{X}$.

Theorem 4.10. Let $(\mathrm{X}, *, 0)$ be a PU-algebra and let $\mathrm{I}$ be a non-empty subset of X. Then I is a PU3-ideal of X if and only if $\mathrm{I}$ is a PU1-ideal of X.

Proof: Let I be a PU3-ideal of X, obviously $0 \in \mathrm{I}$. Let $\mathrm{x} * \mathrm{y}$, $\mathrm{y} *_{\mathrm{z}} \in$ I. Now applying (Definition 2.4. (I), (II)), we get

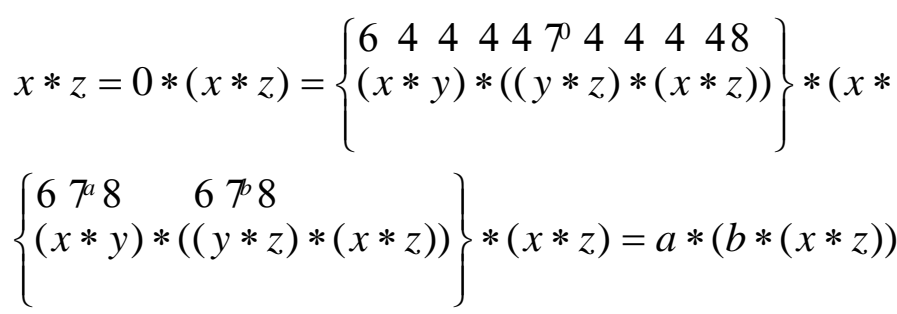

Hence I is a PU1-ideal of X.

Conversely. If I is a PU1-ideal of X, it is clear that $0 \in \mathrm{I}$ and (by Theorem 4.6) $\mathrm{I}$ is an ideal of $\mathrm{X}$.

To prove (ii) ( of Definition 4.9), observe that $(\mathrm{a} *(\mathrm{~b} * \mathrm{x})) *$ $(\mathrm{a} *(\mathrm{~b} * \mathrm{x}))=0 \in \mathrm{I}$, for $\mathrm{a}, \mathrm{b} \in \mathrm{I}$ and $\mathrm{x} \in \mathrm{X}$. By Proposition 2.7.(c), we have $\mathrm{a} *((\mathrm{a} *(\mathrm{~b} * \mathrm{x})) *(\mathrm{~b} * \mathrm{x})) \in \mathrm{I}$. Since $\mathrm{I}$ is an ideal and $\mathrm{a} \in \mathrm{I}$, it follows that $((\mathrm{a} *(\mathrm{~b} * \mathrm{x})) *(\mathrm{~b} * \mathrm{x})) \in \mathrm{I}$. By Proposition 2.7.(c), we have $\mathrm{b} *((\mathrm{a} *(\mathrm{~b} * \mathrm{x})) * \mathrm{x}) \in \mathrm{I}$. Since I is an ideal and $\mathrm{b} \in \mathrm{I}$, it follows that $(\mathrm{a} *(\mathrm{~b} * \mathrm{x})) * \mathrm{x} \in \mathrm{I}$. Therefore I is a PU3-ideal of X.

Lemma 4.11 : If I is a PU3-ideal of a PU-algebra $X$, then for every a $\in \mathrm{I}$ and $\mathrm{x} \in \mathrm{X}$,

$(\mathrm{a} * \mathrm{x}) * \mathrm{x} \in \mathrm{I}$

Proof: Clear.

Corollary $4.12:$ If $\mathrm{a} \in \mathrm{I}$ and $\mathrm{x} \leq \mathrm{a}$, then $\mathrm{x} \in \mathrm{I}$.

Proof: The condition $\mathrm{x} \leq$ a in PU-algebra mean $\mathrm{a} * \mathrm{x}=0$ and by Lemma 4.11, we get $\mathrm{x}=0 * \mathrm{x}=(\mathrm{a} * \mathrm{x}) * \mathrm{x} \in \mathrm{I}$.

Definition 4.13. A non-empty subset I of a PU-algebra (X, *, 0 ) is called a PU4-ideal of $X$ if,

$0 \in \mathrm{I}$,

(ii) $(\mathrm{a} * 0) * \mathrm{~b} \in \mathrm{I}$, for all $\mathrm{a}, \mathrm{b} \in \mathrm{I}$.

Lemma 4.14. If $(\mathrm{X}, *, 0)$ is a PU-algebra, then $(\mathrm{x} *(\mathrm{y} * \mathrm{z})) *$ $\mathrm{z}=(\mathrm{y} * 0) * \mathrm{x}$ for all $\mathrm{x}, \mathrm{y}, \mathrm{z} \in \mathrm{X}$.

Proof: Let $(X, *, 0)$ be a PU-algebra and let $\mathrm{x}, \mathrm{y}, \mathrm{z} \in \mathrm{X}$, then we have that $(\mathrm{x} *(\mathrm{y} * \mathrm{z})) * \mathrm{z}=(\mathrm{z} *(\mathrm{y} * \mathrm{z})) * \mathrm{x}$ (by Proposition 2.8 (2))

$$
\begin{aligned}
& =(\mathrm{y} *(\mathrm{z} * \mathrm{z})) * \mathrm{x} \\
& \text { (by Proposition } 2.7 \text { (c)) } \\
& =(\mathrm{y} * 0) * \mathrm{x} \\
& \text { (by Proposition } 2.7 \text { (a)). }
\end{aligned}
$$

Theorem 4.15. Let $(X, *, 0)$ be a PU-algebra and let I be a non-empty subset of X. Then I is a PU3-ideal of X if and only if $I$ is a PU4-ideal of $X$.

Proof: Follows directly by using Lemma 4.14.

The following result is a direct consequence of Theorems $(4.3,4.6,4.8,4.10$ and 4.15$)$
Theorem 4.16. If $X$ is $P U$-algebra, then the following are equivalent:
(1) I is an ideal of X.
(2) I is a KU-ideal of X.
(3) I is a PU1-ideal of $X$.
(4) I is a PU2-ideal of X.
(5) I is a PU3-ideal of X.
(6) I is a PU4-ideal of X.

Lemma 4.17. Let $(\mathrm{X}, *, 0)$ be a PU-algebra and $\left\{A_{i}\right\}_{i \in I}$ be a family of PU1-ideals of $\mathrm{X}$, then $\mathbf{I}_{i \in I} A_{i}$ is also PU1-ideal of X.

Proof: Let $\mathrm{x}, \mathrm{y}$ and $\mathrm{z} \in \mathrm{X}$ be such that $\mathrm{y} * \mathrm{x}, \mathrm{x} * \mathrm{z} \in$ $\mathbf{1}_{i \in I} A_{i}$

PU1-ideal of $X$ for all $i \in I$. Then $y * z \in A i$ for all $i \in I$, and

*hentee get $I_{\mathrm{y}} * \mathrm{z} \in \mathrm{I}_{i \in I} A_{i}$. Therefore $\mathrm{I}_{i \in I} A_{i}$ is also PU1-ideal of X.

Remark 4.18. Let $(\mathrm{X}, *, 0)$ be a PU-algebra.

1) If $\left\{A_{i}\right\}_{i \in I}$ is a family of KU-ideals of $X$, then $\mathbf{I}_{i \in I} A_{i}$ is also KU-ideal of $\mathrm{X}$.

2) If $\left\{A_{i}\right\}_{i \in I}$ is a family of PU1-ideals of $\mathrm{X}$, then $\mathrm{I}_{i \in I} A_{i}$ is also PU1-ideal of $\mathrm{X}$.

3) If $\left\{A_{i}\right\}_{i \in I}$ is a family of PU2-ideals of $\mathrm{X}$, then $\mathrm{I}_{i \in I} A_{i}$ is also PU2-ideal of $X$.

4) If $\left\{A_{i}\right\}_{i \in I}$ is a family of PU3-ideals of $\mathrm{X}$, then $\mathrm{I}_{i \in I} A_{i}$ is also PU3-ideal of $\mathrm{X}$.

5) If $\left\{A_{i}\right\}_{i \in I}$ is a family of PU4-ideals of X, then $\mathrm{I}_{i \in I} A_{i}$ is also PU4-ideal of $\mathrm{X}$.

Proposition 4.19. If $(\mathrm{X}, *, 0)$ is a PU-algebra, then

(a) $G(X)$ is a PU1-ideal of $X$.

(b) $\mathrm{B}(\mathrm{X})$ is a PU1-ideal of $\mathrm{X}$.

Proof: (a) Clearly $0 \in G(X)$. Let $x * y \in G(X), x \in G(X)$. Then We have that

$$
\begin{aligned}
\mathrm{y} * 0 & =\mathrm{x} *(\mathrm{y} * \mathrm{x}) & & \text { (by Proposition 2.7. (d)) } \\
& =\mathrm{x} *((\mathrm{x} * \mathrm{y}) * 0) & & \text { (by Proposition 2.7. (e)) } \\
& =\mathrm{x} *(\mathrm{x} * \mathrm{y}) & & \text { (by the definition of } \mathrm{G}(\mathrm{X})) .
\end{aligned}
$$

Since $G(X)$ is a PU-sub algebra of $X$, then $y * 0 \in G(X)$. Hence by Proposition 2.7. (b), we have that $\mathrm{y} * 0=(\mathrm{y} * 0) * 0$ $=y$, then $y \in G(X)$, thus $G(X)$ is an ideal of $X$. Therefore by Theorem 4.6., we have that $G(X)$ is a PU1-ideal of $X$.

(b) Clearly $0 \in \mathrm{B}(X)$. Let $\mathrm{x} * \mathrm{y} \in \mathrm{B}(\mathrm{X})$, $\mathrm{x} \in \mathrm{B}(X)$. we have that

$\mathrm{y} * 0=\mathrm{x} *(\mathrm{y} * \mathrm{x})=\mathrm{x} *((\mathrm{x} * \mathrm{y}) * 0)$ (by Proposition 2.7. (d),(e))

$$
=\mathrm{x} * 0=0 \quad \text { (by the definition of } \mathrm{B}(\mathrm{X}) \text { ). }
$$


Then $\mathrm{y} \in \mathrm{B}(\mathrm{X})$, and thus $\mathrm{B}(\mathrm{X})$ is an ideal of $\mathrm{X}$. Therefore by Theorem 4.6., we have that $B(X)$ is a PU1-ideal of $X$.

\section{HOMOMORPHISMS OF PU- ALGEBRA}

Definition 5.1. Let $(X, *, 0)$ and $(X \backslash, \downarrow \backslash, 0 \backslash)$ be PU-algebras. A map $\mathrm{f}: \mathrm{X} \rightarrow \mathrm{X} \backslash$ is called a homomorphism if $\mathrm{f}(\mathrm{x} * \mathrm{y})=\mathrm{f}(\mathrm{x}) * \backslash$ $\mathrm{f}(\mathrm{y})$ for all $\mathrm{x}, \mathrm{y} \in \mathrm{X}$.

Theorem 5.2. Let $(X, *, 0)$ and $(X \backslash, *, 0 \backslash)$ be PU-algebras, and $\mathrm{f}: \mathrm{X} \rightarrow \mathrm{X} \backslash$ be a homomorphism, then

(1) $f(0)=0 \backslash$.

(2) If $S$ is a PU-sub algebra of $X$, then $f(S)$ is a PU-sub algebra of $\mathrm{XI}$.

(3) If $\mathrm{S}$ is a PU-sub algebra of $\mathrm{Xl}$, then $\mathrm{f}-1(\mathrm{~S})$ is a PU-sub algebra of $\mathrm{X}$

(4) If $x \leq y$, then $f(x) \leq f(y)$.

(5) If $B$ is a PU1-ideal of $X I$, then $f-1(B)$ is a PU1-ideal of $X$.

(6) ker $\mathrm{f}$ is a PU1-ideal of $\mathrm{X}$

Proof: (1) $f(0)=f(0 * 0)=f(0) * \backslash f(0)=0 \backslash$ (by Definition 2.4. (I), Definition 5.1. and Proposition 2.7. (a)).

(2) Let $x \backslash, y \backslash \in f(S)$. It follows that $x \backslash=f(x), y \backslash=f(y)$ for some $x, y \in S$. It follows by Definition 5.1., that $x \backslash * \mid y \backslash=f(x)$ $* \backslash \mathrm{f}(\mathrm{y})=\mathrm{f}(\mathrm{x} * \mathrm{y})$. Since $\mathrm{S}$ is a PU-sub algebra of $\mathrm{X}$, then $\mathrm{x} *$ $\mathrm{y} \in \mathrm{S}$ and hence $\mathrm{x} \backslash * \backslash \mathrm{y} \backslash=\mathrm{f}(\mathrm{x} * \mathrm{y}) \in \mathrm{f}(\mathrm{S})$ which complete the proof.

(3) Let $x, y \in f-1(S)$. It follows that $f(x), f(y) \in S$. Since $S$ is a PU-sub algebra of $\mathrm{X} \backslash$ and $\mathrm{f}$ is a homomorphism, then $\mathrm{f}(\mathrm{x}) * \backslash$ $\mathrm{f}(\mathrm{y})=\mathrm{f}(\mathrm{x} * \mathrm{y}) \in \mathrm{S}$. It follows that $\mathrm{x} * \mathrm{y} \in \mathrm{f}-1(\mathrm{~S})$. Hence $\mathrm{f}$ $1(\mathrm{~S})$ is a PU-sub algebra of $\mathrm{X}$.

(4) Since $x \leq y$, then $y * x=0$. It follows that $f(y * x)=f(0)=$ $0 \backslash$. Since $f$ is a homomorphism, then $f(y) * \backslash f(x)=0 \backslash$. Therefore $\mathrm{f}(\mathrm{x}) \leq \mathrm{f}(\mathrm{y})$.

(5) Since B is a PU1-ideal of $X \backslash$, then $0 \backslash \in \mathrm{B}$ (i.e. $\mathrm{f}(0) \in \mathrm{B}$ ). It follows that $0 \in \mathrm{f}-1(\mathrm{~B})$. Let $\mathrm{x}, \mathrm{y}, \mathrm{z} \in \mathrm{X}$ be such that $\mathrm{y} * \mathrm{x} \in \mathrm{f}$ $-1(\mathrm{~B}), \mathrm{x} * \mathrm{z} \in \mathrm{f}-1(\mathrm{~B})$. It follows that $\mathrm{f}(\mathrm{y} * \mathrm{x}) \in \mathrm{B}, \mathrm{f}(\mathrm{x} * \mathrm{z}) \in$ B. Since $\mathrm{f}$ is a homomorphism, then $\mathrm{f}(\mathrm{y}) * \backslash \mathrm{f}(\mathrm{x}) \in \mathrm{B}, \mathrm{f}(\mathrm{x}) * \backslash$ $f(z) \in B$. Since B is a PU1-ideal of $X \backslash$, then $f(y) * \backslash f(z) \in B$. Since $\mathrm{f}$ is a homomorphism, then $\mathrm{f}(\mathrm{y} * \mathrm{z}) \in \mathrm{B}$. It follows that $\mathrm{y} * \mathrm{z} \in \mathrm{f}-1(\mathrm{~B})$. Therefore $\mathrm{f}-1(\mathrm{~B})$ is a PU1-ideal of $\mathrm{X}$.

(6) It is clear that $0 \in \operatorname{ker} f$. Let $x, y, z \in X$ be such that $y * x$, $\mathrm{x} * \mathrm{z} \in$ ker $\mathrm{f}$, then $\mathrm{f}(\mathrm{y} * \mathrm{x})=0 \backslash, \mathrm{f}(\mathrm{x} * \mathrm{z})=0$ \. Since $(\mathrm{X}, *$, $0)$ is PU-algebra, then $\mathrm{y} * \mathrm{x}=(\mathrm{x} * \mathrm{z}) *(\mathrm{y} * \mathrm{z})$. Since $\mathrm{f}$ is a homomorphism, then we have $\mathrm{f}(\mathrm{y} * \mathrm{x})=\mathrm{f}(\mathrm{x} * \mathrm{z}) * \mathrm{f}(\mathrm{y} * \mathrm{z})=$ $0 \backslash$. It follows that $0 \backslash * \backslash \mathrm{f}(\mathrm{y} * \mathrm{z})=0$, hence $\mathrm{f}(\mathrm{y} * \mathrm{z})=0 \backslash$ (i.e. $\mathrm{y}$ $* \mathrm{z} \in$ ker $\mathrm{f}$ ). Therefore ker $\mathrm{f}$ is a PU1-ideal of $\mathrm{X}$

\section{CONCLUSION}

In this manuscript, we introduce a new concept, which called PU-algebra X

We state and prove some theorems about fundamental properties of it. Moreover,we give the concepts of a weak right self-maps, weak left self-maps and investigated some its properties. Further, we have proved that every associative PUalgebra is a group and every p-semisimple algebra is an abelian group. We define the centre of a PU-algebra $\mathrm{X}$ and show that it is a p-semisimple sub-algebra of $X$, which consequently implies that every PU-algebra contains a $\mathrm{p}$ semisimple PU-algebra.

We posed the following problem, is the set $\operatorname{Hom}(\mathrm{X})$ of all PUhomomorphisms of $\mathrm{X}$ into itself, is a PU- algebra? We can proved that it is not always a PU-algebra. However, it may be established that $\operatorname{Hom}(\mathrm{X})$ is a $\mathrm{PU}$-algebra, if $\mathrm{X}$ is an associative PU-algebra. But an associative PU-algebra is again a p-semisimple algebra. Thus homological study of PUalgebras did not develop for PU-algebras in general. The future purpose of this paper is to study the set of all leftregular self- maps of a positive implicative PU-algebra X, we can show that it forms a positive implicative PU-algebra. But no such effort was made for PU-algebras ,We form weakly positive implicative PU-algebras in terms of its Right Selfmaps and Weak Right Self-maps. Further, some properties of Weak Right Self- maps, Weak Left Self-maps and Weak LeftRegular Self-maps can be studied. It can also shown that the set of all Weak Left-Regular Self-maps of a weakly positive implicative PU-algebra $\mathrm{X}$, is a weakly positive implicative PU-algebra. Thus homological study has been made in the class of weakly positive implicative PU-algebras a class which contains the class of p-semisimple PU-algebras, the class of associative PU-algebra, the class of weakly implicative PU-algebras and weakly positive implicative PUalgebras. As is well known, the concept of ideal I plays an important role in PU-algebras $\mathrm{X}$ and a lot of results on ideals can be obtained .We have classified ideals into the following classes as followes : Ideals have elements of $\mathrm{X}$, ideals have elements of $\mathrm{X}$ and I and Ideals have elements of I .We know that every ideal is not necessarily a sub-algebra. Thus a question arises -what type of ideals are sub-algebras? We hope in the further work can answer these open questions .

\section{ACKNOWLEDGMENTS}

The authors are greatly appreciate the referees for their valuable comments and suggestions for improving the paper.

\section{Algorithms for PU-algebra}

Input (X: set with 0 element, : Binary operation)

Output ("X is a PU-algebra or not")

If $\mathrm{X}=\phi$ then;

Go to (1.)

End if

If $0 \notin X$ then go to (1.);

EndIf

Stop: $=$ false

$\mathrm{i}=1$;

While $i \leq|X|$ and not (Stop) do

If $0 * x i \neq x i$, then

Stop: $=$ true

End if

$\mathrm{j}=1$;

While $j \leq|X|$, and not (Stop) do

$\mathrm{k}=1$;

While $k \leq|X|$ and not (stop) do

If $(x i * x k) *(x j * x k) \neq x j * x i$, then

Stop: $=$ true

End if

End while

End if

End while

If stop then 
Output ("X is a PU-algebra")

Else

(1.) Output ("X is not a PU-algebra")

End if

End.

Algorithms for PU-ideal in PU-algebra

Input (X: PU-algebra, I: subset of X)

Output ("I is a PU-ideal of X or not")

If $\mathrm{I}=\phi$ then

Go to (1.);

End if

If $0 \notin$ I then

Go to (1.);

End if

Stop: $=$ false

$\mathrm{i}=1$;

While $i \leq|X|$ and not (stop) do

$\mathrm{j}=1$

While $j \leq|X|$ and not (stop) do

$\mathrm{k}=1$

While $k \leq|X|$ and not (stop) do

If $x j * x i \in I$, and $x i * x k \in I$ then

If $\mathrm{xj}^{*} \mathrm{xk} \notin \mathrm{I}$ then

Stop: $=$ false

End if

End while

End while

End while

If stop then

Output ("I is a PU-ideal of X")

Else
(1.) Output ("I is not ("I is a PU-ideal of X")

End if

End.

\section{REFERENCES}

[1] Q.P. Hu, X. Li, On BCH-algebras, Mathematics Seminar Notes 11 (1983) 313-320.

[2] Y. Imai, K. Iseki, On axiom systems of propositional calculi, XIV Proceedings of Japan Academy 42 (1966) $19-22$.

[3] H.S. Kim, Y.H. Kim, On BE-algebras, Scientiae Mathematicae Japonica Online, e-2006, 1299-1302.

[4] K. Megalai and A. Tamilarasi, Classification of TMalgebra, IJCA Special Issue on "Computer Aided Soft Computing Techniques for Imaging and Biomedical Applications" CASCT. 2010.

[5] B.L. Meng, CI-algebra, Scientiae Mathematicae Japonica Online, e-2009, 695-701.

[6] S.M. Mostafa, M.A. Abd-Elnaby and M.M.M. Yousef, Fuzzy ideals of KU-Algebras, International Mathematical Forum, 6(63) (2011) 3139-3149.

[7] J. Neggers, H.S. Kim, On d-algebras, Mathematica Slovaca 49 (1999) 19-26.

[8] J. Neggers, S.S. Ahn, H.S. Kim, On Q-algebras, International Journal of Mathematics \& Mathematical Sciences 27 (2001) 749-757.

[9] C. Prabpayak and U. Leerawat, On ideas and congurences in KU-algebras, Scientia Magna Journal, 5(1) (2009) 54-57.

[10] C. Prabpayak and U. Leerawat, On isomorphisms of KUalgebras, Scientia Magna Journal, 5(3) (2009) 25-31 